\title{
BELGIM WORKS IN THE FIELD OF MEASURMENTS OF THE CHARACTERISTICS OF LED AND LED LUMINARIES
}

\author{
РАБОТЫ БЕЛГИМ В ОБЛАСТИ ИЗМЕРЕНИЯ \\ ХАРАКТЕРИСТИК СВЕТОДИОДОВ И СВЕТОДИОДНЫХ \\ ИСТОЧНИКОВ ОСВЕЩЕНИЯ
}

\author{
Scums D.V., \\ Tarasova O.B., \\ leading engineer of the Belarusian State Institute of Metrology (Be/GIM), Minsk \\ leading engineer of BelGIM, Minsk \\ Filistovich E.V., \\ head of the department of physical-chemical and optical measurements, BelGIM, Minsk
}

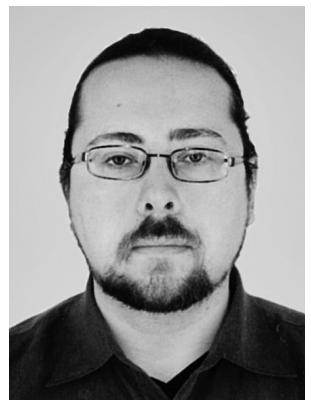

Scums D.V.

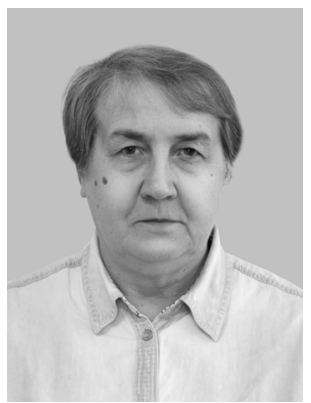

Tarasova O.B.

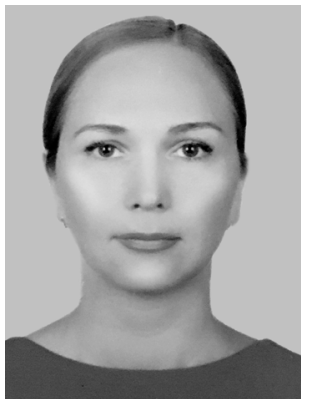

Filistovich E.V.
The works carried out at BelGIM over the past 10 years in order to ensure the uniformity of measurements of the characteristics of LED and LED luminaries is considered. Their short description is given and directions of perspective researches are shown.

Keywords: LED, luminous intensity, luminous flux, chromaticity coordinates, standard lamps.

Рассмотрены работы, выполненные в БелГИМ на протяжении последних 10 лет, по обеспечению единства измерений характеристик светодиодов и светодиодных источников освещения. Представлено их краткое описание и показаны направления перспективных исследований.

Ключевые слова: СИД, сила света, световой поток, координаты иветности, эталонные лампы.

Intensive development of lighting technology, the complexity and improving the ergonomic requirements for the coverage of industrial and living buildings, the use of optical radiation in medicine, the development of new types of lighting in household appliances, in the television makes it necessary to solve more complex metrological tasks in the field of photometry. All the more widespread sources of illumination based on no thermal effect: LED and compact fluorescent lamps. The progress acheved over the past 10 years, in the field of energy-saving light sources, comparable, and in some ways superior to the revolution of the late 19th century, when there was a shift from the lights on the basis of fuel burning to electric light bulbs.

During past ten years in BelGIM a large research work was done to ensure the uniformity of measurements of LEDs and lighting sources on their basis. It includes works on the creation of colorimetric facility of National Standard of luminous intensity, National standard of luminous flux, research of sources of uncertainty of results of measurement of illumination created by LED's, works on evaluation of photobiological safety of LED lighting sources and researches on creation of LED-based standard lamps. This paper will summarize the results of all the studies listed and show the directions of the prospective studies.

\section{Colorimetric facility of National Standard of luminous intensity}

The facility was created in 2009-2011 as part of the modernization work of National Standard of luminous intensity [1-2]. The device consists of following elements: diffuse emission source (DES) based on LEDs, spectroradiometer Konika Minolta CS-1000, power supply E3649A Agilent Technologies, computer.

The integrating sphere and a group of LEDs make up the core of the DES. LED emission sources have been developed and constructed in the Institute of Physics of the Belarussian National Academy of Sciences based on LEDs of the green, red, blue, yellow and white colors. The main elements of the construction are the following ones: LED, light-diffusing plate, refrigerating system 


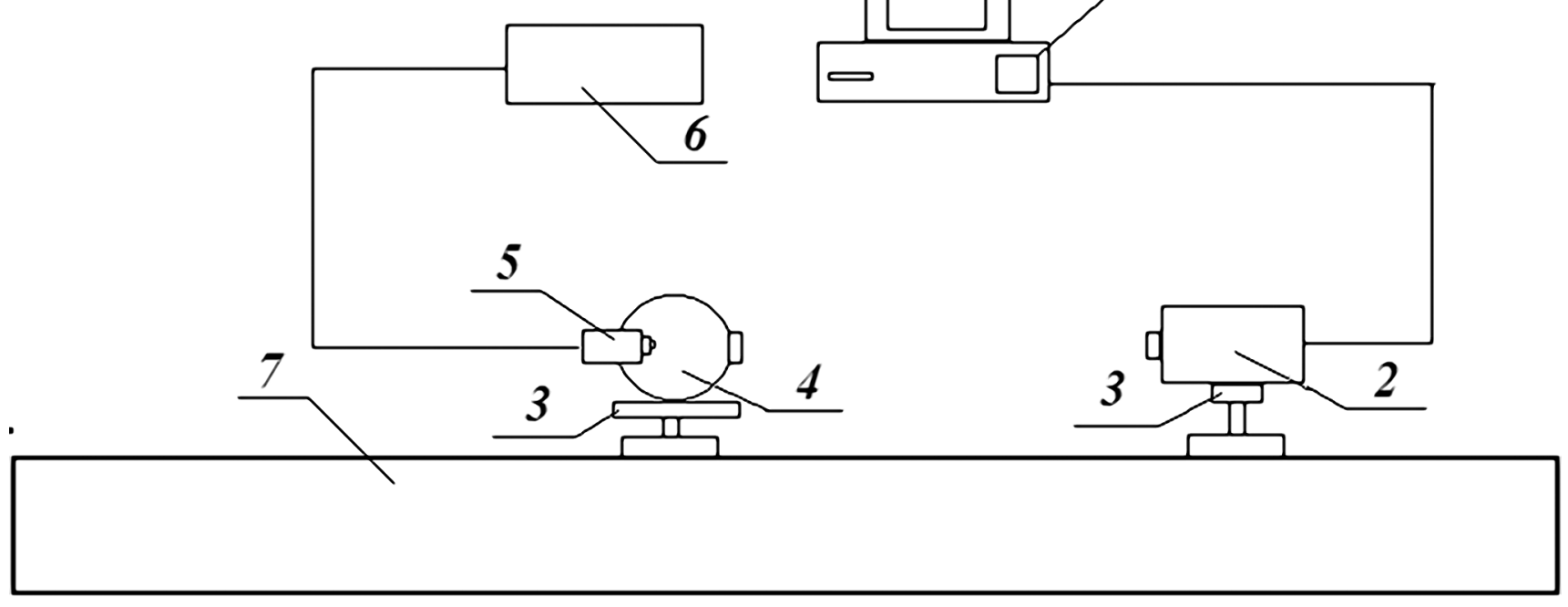

Fig. 1. Block-scheme of the colorimetric facility: 1 - computer; $2-$ spectroradiometer; $3-$ positioning stages; $4-$ integrating sphere; 5 - LED emission source; 6 - power supply; 7 - beam table

(fan-cooled) and power supply. During research of the device characteristics were determined: uncertainty 0,003 chromaticity unit, standard deviation $-0,0004$. Facility show very good longtime stability.

\section{National standard of luminous flux}

The standard was created in 2012-2015 [3]. The main elements of photometric and the LEDs units are two integrating spheres: ISP 2000 with an inner diameter of $1900 \mathrm{~mm}$ (photometric unit), ISP 1000 with inner diameter of $1000 \mathrm{~mm}$ (LEDs unit) and a spectroradiometer CAS140CT-156 operating in the wavelength range from 300 to $1100 \mathrm{~nm}$, manufactured by Instrument Systems (Germany). The photometric unit is equipped with working and primary standards on the base of luminous flux Tungsten Halogen Lamps W 150, manufactured by Pimacs and KRISS (Korea), and the LED unit - the reference LED sources ACS540 (manufactured by Instrument Systems) having a light color white, red, blue and green. The main functions of the photometric unit - reproduction, storage and transmission of luminous flux unit to the subordinate standards and working measuring instruments for measuring of large radiation sources and products based on them. The main functions of the LEDs unit - storage and transmission of luminous flux unit to the subordinate standards and working instruments measuring small-sized light sources and products based on them. The structure of photometric unit includes an external radiation source, which is the result of joint work of BelGIM, Institute of Physics, National Academy of Sciences of Belarus and Belarusian company "Tsersis Analytic". The need to create an external radiation source is that it allows to reproduce unit of the luminous flux by so-called "absolute integrating sphere method". This method is correlated with the method of the reproduction of the unit of luminous intensity, which is implemented on the National standard NS RB8-02, located in BelGIM. Goniophotometric unit is designed to measure the characteristics of the spatial distribution of radiation of different continuous radiation sources, as well as storage and transmission unit of luminous flux of the light source with an arbitrary spatial distribution and large-sized lighting products. The basis of goniometric unit is goniometer LGS-350 and spectroradiometer CAS140CT-152 (spectral range from $200 \mathrm{~nm}$ to $800 \mathrm{~nm}$ ) manufactured by Instrument Systems (Germany). National standard of luminous flux of the Republic of Belarus are created. It has the following metrological characteristics:

- Range of reproducing of the unit of luminous flux is from 10 to $1500 \mathrm{~lm}$.

- Random component of the uncertainty of luminous flux unit reproduction is $0,2 \cdot 10^{-2}$.

- Unexcluded measurement error is $0,5 \cdot 10^{-2}$.

- Relative expanded uncertainty of the standard is $0.52 \%$.

\section{Research of sources of uncertainty of results of measurement of illumination created by LED's}

Work has been performed in 2009-2014 [4-5]. One of the main problems of assessing correctness of operation of the light source is to measure created by it illumination. This value is strictly rationed number of technical regulations, and should be controlled carefully. However, all types luxmeters used in Belarus calibrated or tested against standard source type A, 


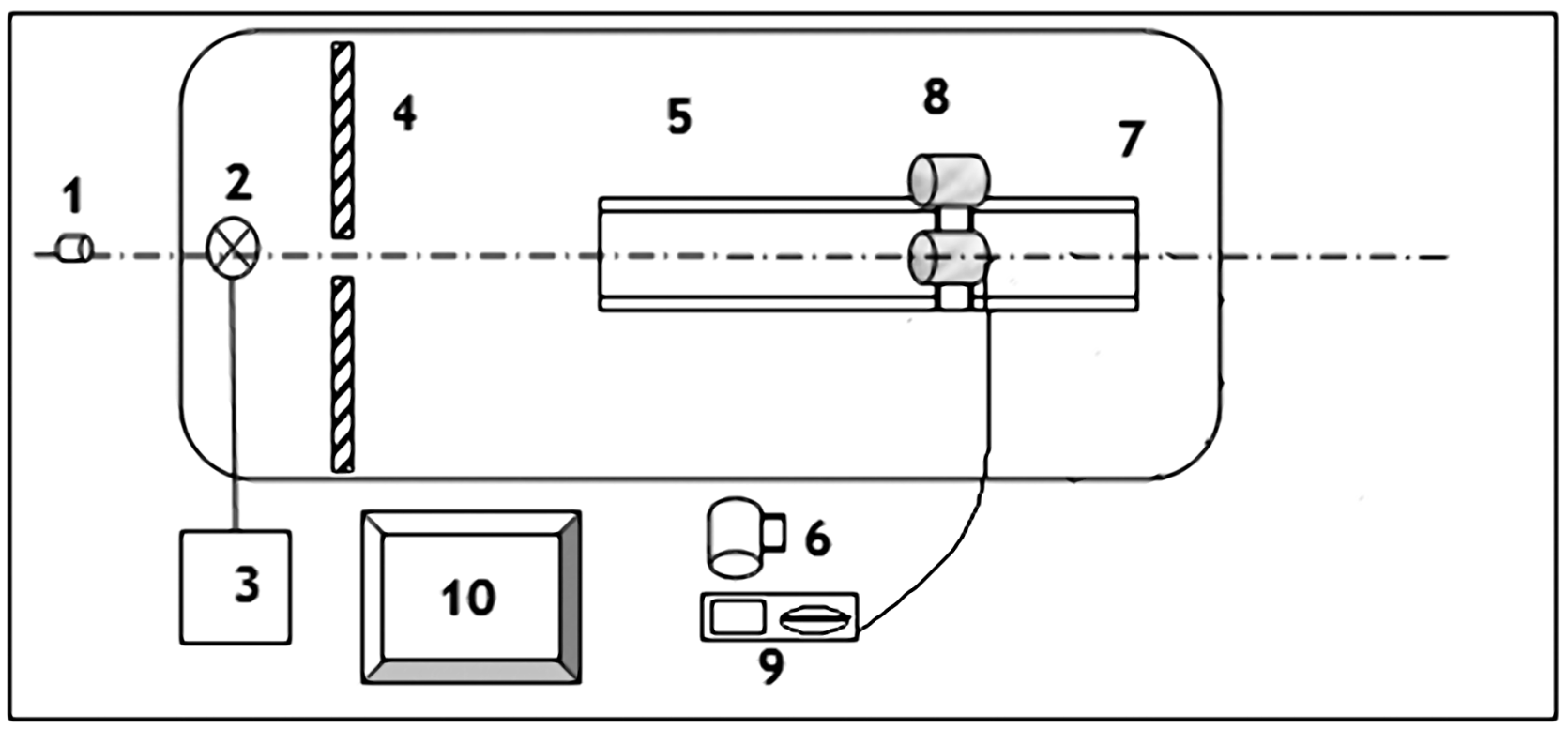

Fig. 2. Block diagram of the automated facility for calibration of luxmeters/photometers UPF-2: 1 - laser pointer; 2 - light source; 3 - power supply of the light source; 4 - attenuators of the luminous flux; 5 - mobile automated platform 8MT295-340-2,5; 6 - a video camera; 7 - automatic mobile platform 8MT175; 8 - standard optical detector and DUT in the holder; 9 - DUT; 10 - a personal computer

which relative spectral distribution of the radiation power is much different from the spectral distribution of the LED. Theoretical studies show that as a result of it the measurement error of illumination should rise significantly [4]. The objective of this phase of the work was to evaluate the measurement uncertainty created by the LEDs and lighting products based on them. As a substantial amount illumination measurement is carried out in the workplace, the residential and industrial areas, but not in specialized laboratories, as a test, we selected the most common types in the country luxmeters: ТКА-ПКМ, ТКА-Люкс (Russia) and the photometer-brightnessmeter TЭC 0693 (Ukraine). As a radiation source, we used standard source based on white LEDs from the National standard of units of luminous intensity and illuminance of the Republic of Belarus (NLII) [2]. The measurements were carried out on NLII and in the Institute of Physics of the NAS of Belarus on the "Prostor LD-SED" installation as recommended by the CIE127-2007. Initially, to determine the accuracy of the test luxmeters they were measured against type A source. In this role were used photometric lamp Wi $41 / 5$ from the NLII. Further lamp Wi $41 / 5$ is replaced by LED and measurements were taken at the same illumination as created by the type A source at a distance $\mathrm{d}=523 \mathrm{~mm}$ and standard conditions CIE A d $=316 \mathrm{~mm}$ as recommended by CIE127-2007. The measurements under standard conditions ICE B is not carried out, as it led to the overload of the test equipment. The reference value of illumination was obtained by calculating from the measured intensity LED under the law of "inverse squares". From results it was founded that the transition from incandescent lighting to LED illumination sources, measurement error increases, but not much higher than the values normalized for the type of device by manufacturer [5]. This eliminates the need for a massive upgrade of the park luxmeters operating in the country. However, since the error of illumination measurement is slightly higher than the normalized value of the manufacturer, with registration in the Register of measuring devices approved for use in the field of legal metrology is necessary to consider separately indicate the uncertainty of measurement for incandescent and LED.

According to received results in phase 2 of research was created automated facility for calibration of luxmeters/photometers UPF-2 [6].

The Facility consists of four units. There are the unit of the linear positioning and the luminous flux adjustment, the unit of electric measurements equipment and standard receivers, the unit of automatic registration of measurement results and the unit of light source based on a combination of a hemispherical light source (HLS) [5], which consists of a hemisphere and a reflector. The inner surface of the hemisphere is coated with barium sulfate. The ratio of the hemisphere diameter to the diameter of the output aperture ration is $5 / 1$. The illumination block of the HLS has lamps and LEDs-source. LEDs-sources consist of the 16-th LEDs: Lumileds Luxeon S1000 LXS8-PW27 (8 pieces) and Luxeon S1000 LXS9-PW30 (8 pieces). The 8 Lumileds Luxeon S1000 LXS8-PW27 have the color correction temperature between $2725 \mathrm{~K}$ and $\mathrm{K}$, the 8 Luxeon S1000 LXS9-PW30 have the color correction temperature between 3945 and to 3129. These color temperatures were so chosen that the produce mean value of the CCT is about $2900 \mathrm{~K}$. According to test 
results HLS showed high stability and reproducibility. Drift of illuminance produced per 3 hours is not higher than $\pm 0,25 \%$. The unevenness of the light spot at a distance of $0.5 \mathrm{~m}$ was $2,23 \%$. Correlated color temperature to $2863 \mathrm{~K}$.

\section{Researches on creation of LED-based standard lamps}

Situation with the metrological support of the luminous flux measurement is significantly complicated in recent years. Firstly, according to the requirements of international standards for calibration of photometric sphere's you must use a source with the spectral distribution of the radiation power as close as possible to the spectral distribution of DUT. Secondly, after the entry into force of the Directive EC2005/32 / EG the world's major producers finished the production of incandescent light bulbs. At the same time, it was closed and the production of standard photometric lamps. Similar production in the countries of the former USSR were closed in the 90's. Thirdly in [7] it was shown that use of LED-based standard source jointly with PQED-detector can significant reduce uncertainty of reproduction of units of luminous intensity and luminous flux. Based on the above considerations, this year BelGIM started work on the development of standard LED-based lamps. On phase one it was decided to create model of not cooled LED-based lamp. Analysis of similar studies has shown that a light sources created at NIM, China, shows sufficient stability [8]. As DUT we use COB LED and LED-filament lamps. First results of research showed encouraging results (example of measurement results see in table).

The results of stability studies luminous flux standard lamps layouts

\begin{tabular}{|c|c|c|c|c|c|}
\hline \multirow{2}{*}{ Lamp type } & \multicolumn{5}{|c|}{} \\
\cline { 2 - 6 } & $\mathbf{1 0} \mathbf{h}$ & $\mathbf{2 0} \mathbf{~ h}$ & $\mathbf{3 0} \mathbf{~ h}$ & $\mathbf{4 0} \mathbf{~ h}$ & $\mathbf{5 0}$ h \\
\hline LED-filament 1 & 830 & 826 & 812 & 798 & 770 \\
\hline LED-filament 2 & 850 & 824 & 816 & 803 & 890 \\
\hline LED-luminophore 1 & 1550 & 1530 & 1525 & 1521 & 1518 \\
\hline LED-luminophore 1 & 1550 & 1550 & 1540 & 1530 & 1525 \\
\hline
\end{tabular}

But after 55-60 hours of burning all COB-lamps burnt out. The use also had to be abandoned due to insufficient stability. In our opinion, this was due to the use of adherent hemispherical diffuser. This design was chosen to achieve the most uniform light distribution, as close as possible to that of conventional luminous flux standard lamps. Which prevented sufficient heat transfer from LED chip. The use of LED-filament lamp also had to be abandoned due to insufficient stability. Based on the results obtained in the design of lamps, a thermal control system based on Peltier elements was added. Currently, the lamps undergo the procedure of primary aging.
In phase 2 which is scheduled for next year planned research of long-term stability of lamps and reproducing the reproduction of a unit of luminous intensity according to [7]. For this purpose, PQEDdetector was purchased.

\section{Conclusion}

During past ten years in BelGIM a large research work was done to ensure the uniformity of measurements of LEDs and lighting sources on their basis. It includes works on the creation of colorimetric facility of National Standard of luminous intensity, National standard of luminous flux, research of sources of uncertainty of results of measurement of illumination created by LED's, works on evaluation of photobiological safety of LED lighting sources and researches on creation of LED-based standard lamps. The obtained results of research and created facilities and standards are claimed by consumers in the Republic of Belarus and abroad.

\section{References}

1. Lysenok O.N., Nikonenko S.V., Scums D.V., Tarasova O.B. Results of the study of the color characteristics of a diffuse source of radiation, created on the basis of light-emitting diodes. Proceedings of the Scientific and Practical Conference "Metrology - 2009". Minsk. April 14-15, 2009, pp. 134-137.

2. Lysenok O.N., Nikonenko S.V., Scums D.V., Tarasova O. B. National Standard of luminous intensity of the Republic of Belarus - colorimetric facility. Proc. of the 4th international conference on metrology. Jerusalem, Israel. May 23-24, 2011.

3. Scums D.V., Tarasova O. B., Dlugunovich V.A., Nikonenko S.V. National standard of luminous flux of the Republic of Belarus. Proceedings of the 13th International Conference on New Developments and Applications in Optical Radiometry (NEWRAD2017), Miraikan Hall, in Odaiba, Tokyo. 13-16 June, 2017.

4. Scums D.V. Energy saving lamps as a problem of photometic metrology. Proc. of V International Competition "The Best Young metrologist of COOMET". PTB Braunschweig, Gernany. 11 to 13 June, 2013.

5. Scums D.V., Nikonenko S.V., Danilchyk A.V., Zhdanovskii V.A., Kreidzich A.V., Lutsenko, E.V. New type of source for luxmeters calibration. Proceedings of the 28th Session of the CIE. Manchester, United Kingdom. 28 June - 4 July, 2015.

6. Scums D.V. Automated facility for calibration of luxmeters/photometers UPF-2. Proc. of VI International Competition "The Best Young metrologist of COOMET". Kiev, Ukraine. 17 to 18 June, 2015. 
7. Dönsberg T, Pulli T, Poikonen T, Baumgartner H, Vaskuri A, Sildoja M, Manoocheri F, Kärhä P and Ikonen E. "New source and detectortechnology for the realization of photometric units" Metrologia 51, S276-S281 (2014).

8. Joanne C. Zwinkels. CCPR Activities Related to LED-based Calibration Standards, available at: http://www.researchgate.net/profile/Joanne Zwinkels/publication/298212170_CCPR_Activities_ Related_to_LED-based_Calibration_Standards
/links/56e6e0af08ae85e780cf9a8c/CCPR-ActivitiesRelated-to-LED-based-Calibration-Standards.pdf (accessed 17 September 2017)

Статья рекомендована к публикации доктором технических наук, ведущим научным сотрудником А.Д. Купко.

The article is recommended for publication by A.D. Kupko, Doctor of Technical Sciences, Leading Researcher. 